\title{
İskelet traksiyonunda temel prensipler
}

\author{
Basic principles in skeletal traction
}

\author{
Ibrahim Alper Yavuz, Cahit Koçak, Özdamar Fuad Öken
}

SBÜ Ankara Numune Eğitim ve Araştırma Hastanesi, Ortopedi ve Travmatoloji Kliniği, Ankara

\begin{abstract}
İskelet traksiyonu ortopedi pratiğinde halen geçerliliğini koruyan etkili ve tarihsel bir yöntemdir. Günümüzde, özellikle alt ekstremitede güçlü kasların çekmesine bağlı kırıktaki ayrışmayı kontrol edebilmek ve böylece ameliyat öncesi dönemde ağrı ve ödem kontrolü yapabilmek için sıklıkla uygulanmaktadır. Konservatif tedavi yöntemi olarak ise, özellikle ameliyat planlanmayan asetabulum kırıklarında kullanımı mevcuttur. En çok tercih edilen bölgeler, distal femur, proksimal tibia ve kalkaneustur. Girişimsel bir işlem olması ve anestezi (genel ve/veya lokal) gerektirmesi dezavantaj olarak görülebilir, ancak doğru uygulandığı takdirde hem hasta hem de cerrah açısından avantajları daha fazladır.
\end{abstract}

Anahtar sözcükler: iskelet traksiyonu; iskelet traksiyonu uygulama prensipleri; pin yerleşim bölgeleri; iskelet traksiyonu komplikasyonları skelet traksiyonu, ortopedi pratiğinde halen geçerliliğini koruyan tarihsel ve etkili bir yöntemdir. ${ }^{[1-3]}$ Özellikle pelvis ve alt ekstremite yaralanmalarında, kırıkta yer değiştirmeye neden olan güçlü kasların çekme kuvvetini karşılayabilmek adına etkili bir yöntemdir. Birkaç istisna dışında, nihai tedavi yöntemi olarak kullanılmaktan ziyade, özellikle ameliyat öncesi dönemde ödem ve ağrı kontrolü, yani hastanın ameliyat hazırlı̆̆ının bir aşaması olarak daha sıklıkla uygulanmaktadır. Dezavantajları ise; invaziv bir işlem olması, bölgesel veya genel anestezi ihtiyacı olması, enfeksiyon/osteomiyelit riski ve hastanın mobilize olamaması olarak sıralanabilir. Traksiyonda kullanılacak malzemelerin doğru seçilmesi, pin yerleşimi sonrası doğru bir traksiyon mekanizması kurulması ve düzenli bir takip programı ile, iyi sonuçların alınmama ihtimali çok düşüktür. Bu nedenle, ortopedi pratiğindeki önemini korumaya devam edeceği düşünülmektedir.
Skeletal traction is an effective and historical method that still maintains its validity in orthopedic practice. Nowadays it is frequently applied to control pain and edema in the preoperative period, especially in the lower extremity due to strong muscle pulling. As a conservative treatment method, it is used especially in acetabulum fractures which are not planned for operation. The most preferred regions are: distal femur, proximal tibia, and calcaneus. Being an interventional procedure and anesthesia (general and/or local) may be seen as disadvantages, but if applied correctly it is more advantageous both for the patient and the surgeon.

Key words: skeletal traction; skeletal traction practice principles; pin placement regions; complications of skeletal traction

\section{TRAKSIYON YÖNTEMLERI}

Traksiyon tiplerine bakıldığında prensip olarak ikiye ayrilabilir:

1- Sabit traksiyon: Traksiyon uygulaması sabit bir karşı traksiyona karşı yapılmaktadır. (halo-pelvik traksiyon, Thomas splint, Roger Anderson well-leg traksiyon)

2- Kayıcı traksiyon: Vücudun tümü veya bir kısmı yer çekimi etkisi altında hareket ettirilerek, vücut ağırlığı traksiyon sağlamak için kullanılır. (alt ekstremite cilt ve iskelet traksiyonları...)

Uygulanma biçimine göre ise traksiyonlar üçe ayrılabilir:

1- Manuel traksiyon: Kırık redüksiyonu sırasında kullanılmaktadır.

- Illetişim adresi: Doç. Dr. Özdamar Fuad Öken, SBÜ Ankara Numune Eğitim ve Araştırma Hastanesi, Ortopedi ve Travmatoloji Kliniği, Ankara Tel: 0312 - 5085028 e-posta: fuadoken@yahoo.com

- Geliş tarihi: 1 Ağustos 2018 Kabul tarihi: 1 Ağustos 2018 
2- Cilt traksiyonu: Adhesiv ve adhesiv olmayan olmak üzere iki çeşittir. Adhesiv cilt traksiyonunda maximum 6-7 kg kurvet uygulanabilir. Atrofik cildi olan yaşlı hastalarda adhesiv olmayan cilt traksiyonu önerilmekle birlikte, maksimum 4-5 kg kuvvet uygulanabilir. (Buck's traksiyonu, Hamilton-Russel traksiyonu, Tulloch-Brown traksiyonu...)

3- iskelet traksiyonu: Sık kullanılmaktadır. Konservatif tedavi yöntemi olarak da kullanılabilmektedir. Daha efektif ve kontrollü bir güç uygulama olanağı sağlamaktadır. ${ }^{[4]}$

\section{ISKELET TRAKSIYONU}

İsviçreli cerrah Fritz Steinmann (1870-1930) tarafindan tasarlanan Steinmann çivileri ile birlikte, 1908'den itibaren iskelet traksiyonu sık kullanılan bir yöntem olarak ortopedi pratiğine girmiştir. Günümüzde ise, özellikle alt ekstremite yaralanmalarında, eskisi kadar sık olmamakla birlikte kullanılmaya devam etmektedir. Nihai tedavi yöntemi olarak kullanılmaktan ziyade (konservatif tedavi planlanan pelvis ve asetabulum kırıkları hariç), özellikle ameliyat öncesi dönemde ödem ve ağıı kontrolü, yani hastanın ameliyat hazırlığının bir aşaması olarak uygulanmaktadır.

Özellikle alt ekstremitede, güçlü kasların kırıkta yarattığı deplasman kuvvetini karşılayabilmek adına etkili bir yöntemdir. Traksiyona yardımcı mekanizmaların kullanılması ile birlikte, üç planlı vektörel bir traksiyon kuvveti sağlar. Bu sayede, kırığa üç planda tam hakimiyet sağlanabilmektedir.

Dezavantajları ise; invaziv bir girişim olması, uygulanabilmesi için lokal veya genel anestezi ihtiyacı olması, bağ dokusu hasarı riski, enfeksiyon/osteomiyelit riski, eklem kontraktürü riski ve hastanın mobilize olamaması olarak sıralanabilir. Ancak, doğru uygulandığında bu komplikasyonlarla karşılaşma ihtimali çok düşüktür. ${ }^{[5]}$

\section{İskelet Traksiyonu Uygulama Endikasyonları}

- Cilt traksiyonu için uygun bir sağlam cildin olmaması (dermabrazyon, açık yara, kesi vb.)

- Traksiyon için 6,5 kilogramdan daha fazla ağırlık gereken hastalar

- Konservatif tedavi edilecek kırıklar

\section{İskelet Traksiyonu Uygulama Kontrendikasyonları}

- Hasta uyumsuzluğu

- Pin uygulanacak bölgede enfeksiyon

- Steril şartların sağlanamaması

\section{İskelet Traksiyonu Uygulama Sonrası} Görülebilecek Komplikasyonlar

- Enfeksiyonun kemik içine yayılma riski

- Kırıkta ayrışma

- Bağ hasarı

- Epifizyel büyüme plağının hasarlanması

- Ciltte çökük skar

- Hastada uzamış hareketsizliğe bağlı gelişebilen sorunlar

\section{İskelet Traksiyonunda Seçilecek Malzemeler}

Kirschner telleri iskelet traksiyonu için çocuk hastalarda ve üst ekstremite kırıklarında kullanılabilmektedir. Kirschner teli (1,6 mm), kemiği kesmeden femurun alt ucunda 22 kg'lık bir çekiş ağırlığına dayanabilir. Ancak, devamlı hareket ve daha yüksek basınç gevşeme ve enfeksiyona yatkınlık yaratır. Bu nedenlerle, iskelet traksiyonunda günümüzde Steinmann pinleri kullanılmaktadır.

Steinmann pinleri 3-6 mm çaplarda ve $150-300 \mathrm{~mm}$ uzunluklarda üretilmektedir. Sivri uç, genellikle trokar veya elmas uç tasarımıdır, ancak küçük oluklar içeren uçlar da mevcuttur. Oluklu olanlar, trokar veya elmas uçlarda olduğu gibi kemiği kazıyan değil, kemiği kesen pozitif bir eğim açısına sahiptir. Bu oluklar, kemikte yapılan delikten geçişi kolaylaştırır ve daha az ısı açığa çıkartır.

Steinmann telinin şaftı pürüzsüz veya yivlidir. Ortası yivli olanlara Denham pinler denmektedir. Denham pinlerinde yivli bölüm yivsiz kısımdan $0,5 \mathrm{~mm}$ daha büyük olduğundan, bunların tutunması daha sağlamdır. Denham pinlerinin avantajı; kortekse daha iyi tutunarak sıyrılmayı önlemesi, gevşeme ve enfeksiyon riskini azaltmasıdır. Osteoporotik hastalarda ve kansellöz kemikte (özellikle kalkaneusta) daha iyi tutunma sağlaması ciddi bir avantaj sağlamaktadır (Şekil 1).

Pin yerleşimi sonrası, bunu traksiyona uygun hale getirmek için en etkili yöntem, Böhler üzengisi/yayı kullanılmasıdır. Devamında, bir ip yaydan geçirilerek traksiyona başlanabilir. Böhler yayı bulunamadığı durumlarda, Böhler yayı kadar efektif olmasa da, ipler Steinmann pininin her iki ucundan tespit edilip yay haline getirilerek traksiyon yapılabilir (Şekil 2).

Alt ekstremite kırıklarında Braun-Böhler splinti sıklıkla kullanılmaktadır. Avantajları; alt ekstremitede birçok bölgenin kırığında kullanılabilmesi, alt ekstremiteyi rahat bir pozisyonda tutması, traksiyon açılarının değiştirilebilmesi, yara bakımının kolay olması ve eş zamanlı iki farklı kemikten (distal femur / proksimal tibia, kalkaneus / distal tibia) traksiyon sağlanabilmesidir (Şekil 3). 

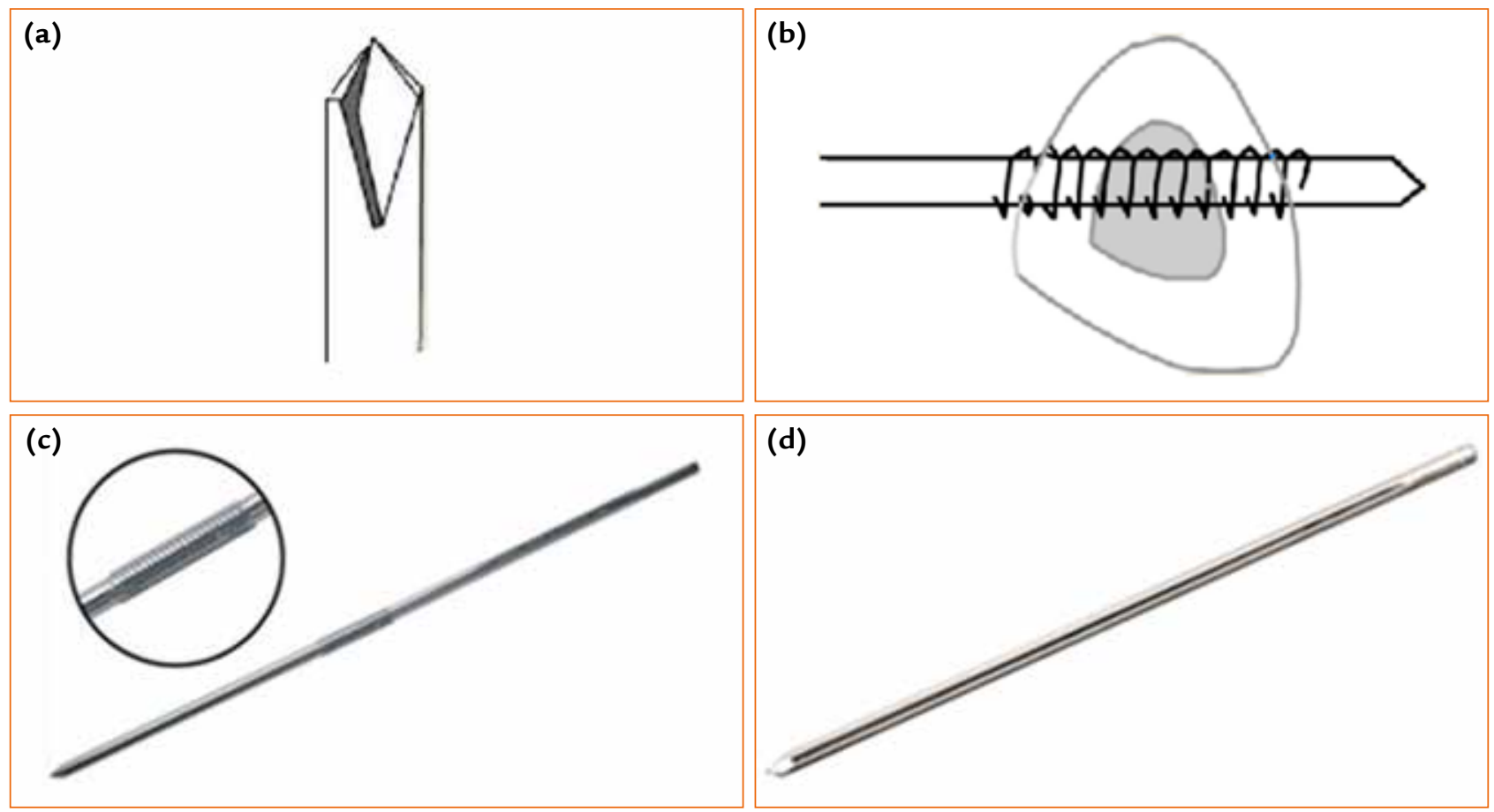

Şekil 1. a-d. Steinmann pininin açılı ucu (a). Denham pininin kullanımı (b). Denham pini ve orta kısmındaki yiv yapısı (c). Steinmann pini (d).

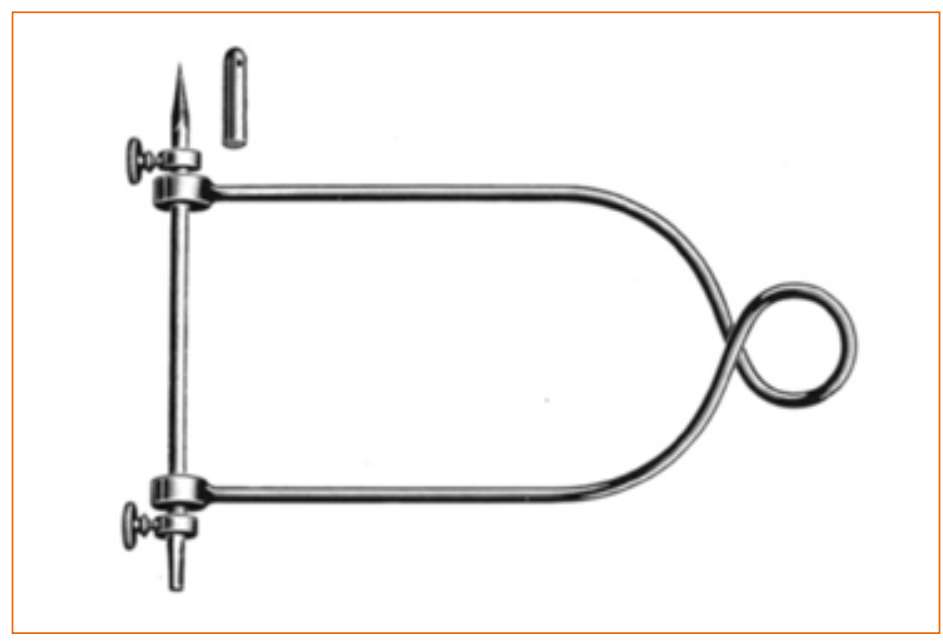

Şekil 2. Böhler üzengisi/yayı.

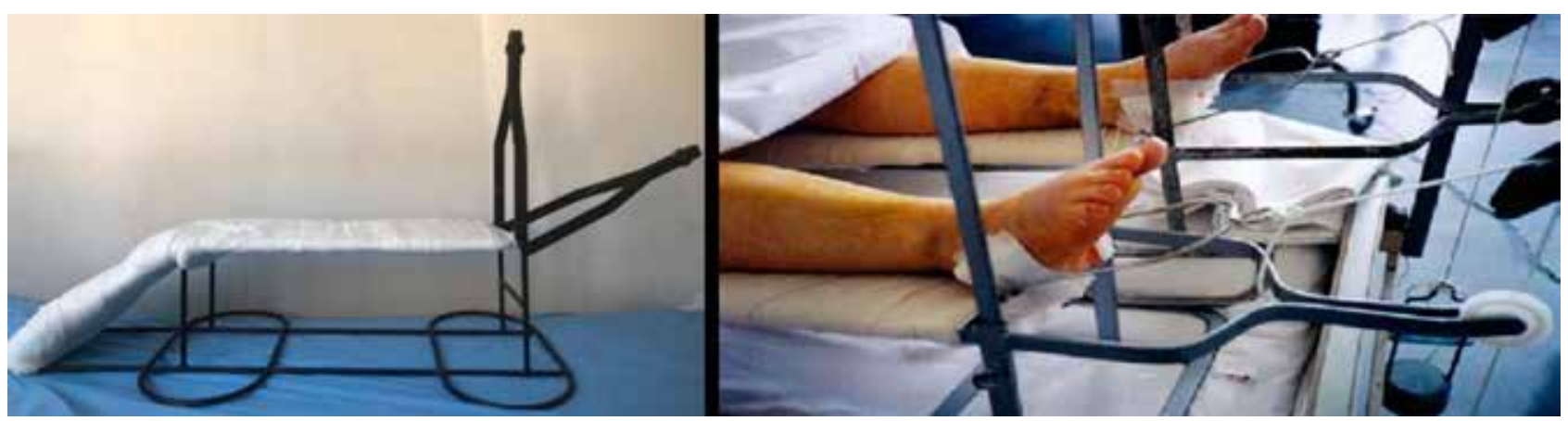

Şekil 3. Kliniğimizde kullanılan Braun-Böhler aparatı ve uygulanması. 


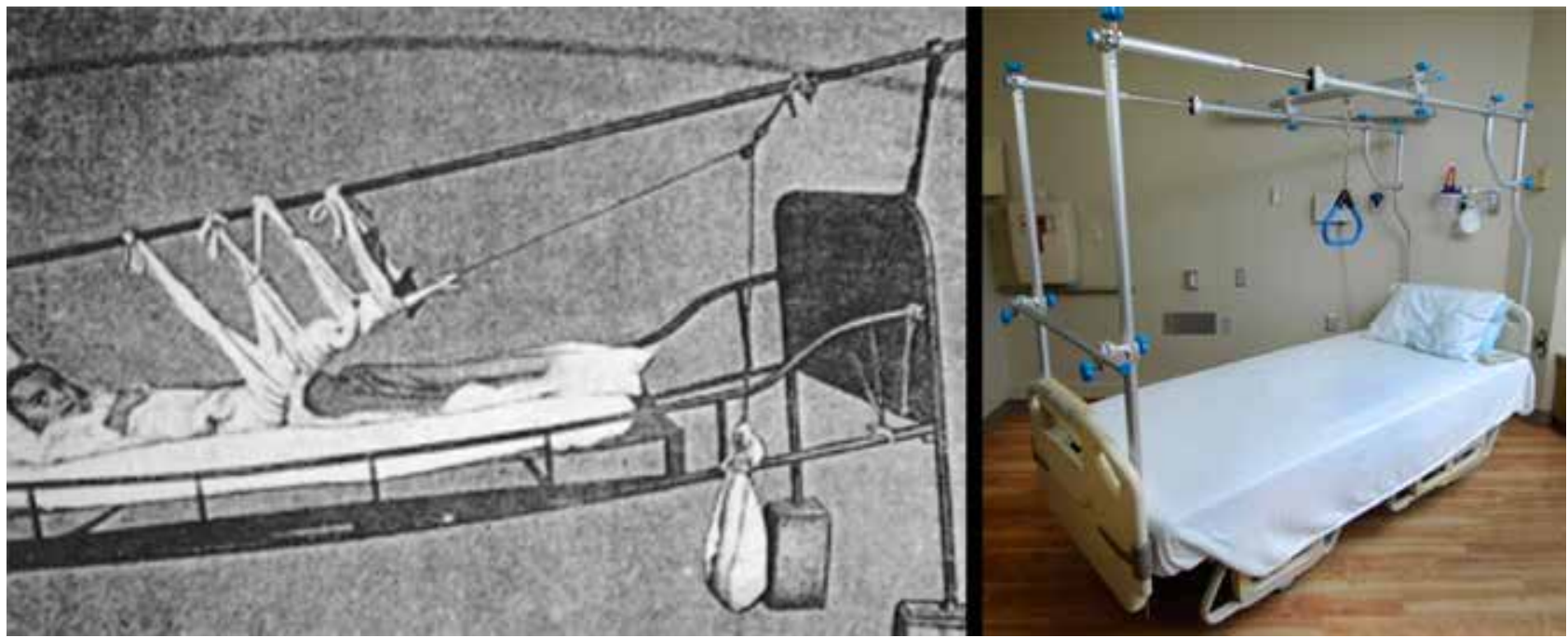

Şekil 4. Illk orijinal Balkan beam frame ve günümüzde kullanılan Balkan beam frame.

Balkan beam frame ise, 1911'de Hırvatistan'da Prof. Vatroslav Florschutz tarafindan tasarlanıp kullanılmaya başlanmış bir sistemdir. Hasta yatağı üzerine monte edilebilen bu mekanizma ve mekanizma üzerinde bulunan makara sistemleri sayesinde, devamlı ve istenilen açıda traksiyon sağlanabilmektedir (Şekil 4). ${ }^{[6,7]}$

\section{ISKELET TRAKSIYONU UYGULANMASI}

\section{Genel Prensipler}

- Öncelikle hastayı bu konuda bilgilendirin onamını alın.

- Hastaya uygun pozisyon verin.

- Steril bir ortam ve steril bir örtünme sağlayın.

- Hastanın lokal anesteziklere karşı allerjisi olup olmadığını sorgulayın.

- Ciltten başlayarak derin dokulara ve özellikle periosta önce pin giriş tarafından sonra pin çıkış tarafindan lokal anestezi uygulayın.

- Pin giriş yerinden traksiyon eksenine paralel, kemiğe dik olacak şekilde küçük bir insizyon yapın (sık yapılan hata, daha anteriordan girmeye bağlı, cildin posteriora doğru gerilmesidir).

- Mümkünse pin yerleştirme işlemini floroskopi eşliğinde yapın.

- Önce yüksek frekanslı bir drill ile, doğrultunuzu ayarlayarak drilleyin (Steinmann pinlerinin ucu yeterince keskin olmadığı için, kortekslerde ısıya bağlı nekroza neden olarak, gevşemeye ve enfeksiyona yatkınlık yaratmaktadır).
- Doğrultuyu ayarlarken tek kişinin iki ekseni birden kontrol etmesi zor olacağı için, diğer sağlık personelinden yardım isteyin.

- Drillerken ve Steinmann pinini geçerken yumuşak dokuya zarar vermemek için, mutlaka bir drill koruyucu (sleeve) kullanın.

- Karşı korteksi geçtikten sonra, Steinmann pininin çıkacağı yerden, yine traksiyon eksenine paralel bir cilt insizyonu yapın (bu, Steinmann pininin cilt ve cilt altı dokuyu sarmasını engelleyerek gerilmeyi önleyecek ve dolaşımı bozmayacaktır).

- Hastayı, personeli ve kendinizi yaralamamak için, Steinmann pininin keskin ucunu örtün.

- Giriş ve çıkış yerlerinde cildin gergin olduğunu düşünürseniz, cilt kesilerini genişletin (Şekil 5)

\section{SIK UYGULANAN PIN YERLEŞiM BÖLGELERi}

\section{Olekranon}

- Humerus cisim kırıkları (lateral olekranon traksiyonu) ile suprakondiler / distal humerus kırıklarında (olekranon pin traksiyonu) kullanılır. Çocuklarda, özellikle deplase parçalı suprakondiler kırıklarda kullanımı ile, sonuçların iyi olduğunu bildiren yayınlar mevcuttur. ${ }^{[8-10]}$

- Kirschner teli tercih edilir.

- Proksimal ulnanın tip'inden yaklaşık $3 \mathrm{~cm}$ distaline yerleştirilir.

- Mediyalden laterale doğru yerleştirilir.

- Ulnar sinire dikkat edilmelidir (Şekil 6). 


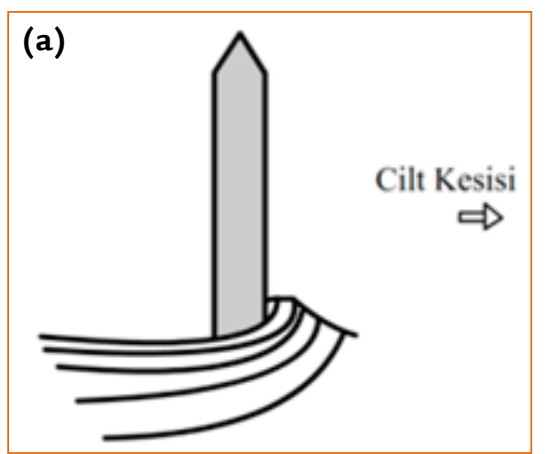

(b)

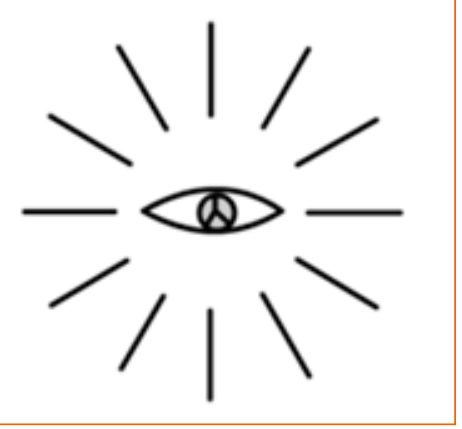

Şekil 5. a, b. Steinmann pininin çıkışında cilt kesisi yapılmaması üzerine, Steinmann'ın cilt ve cilt altı dokuyu sarması (a). Cilt kesisi sonrası gerilimin yumuşak dokuda eşit şekilde dağılması (b).
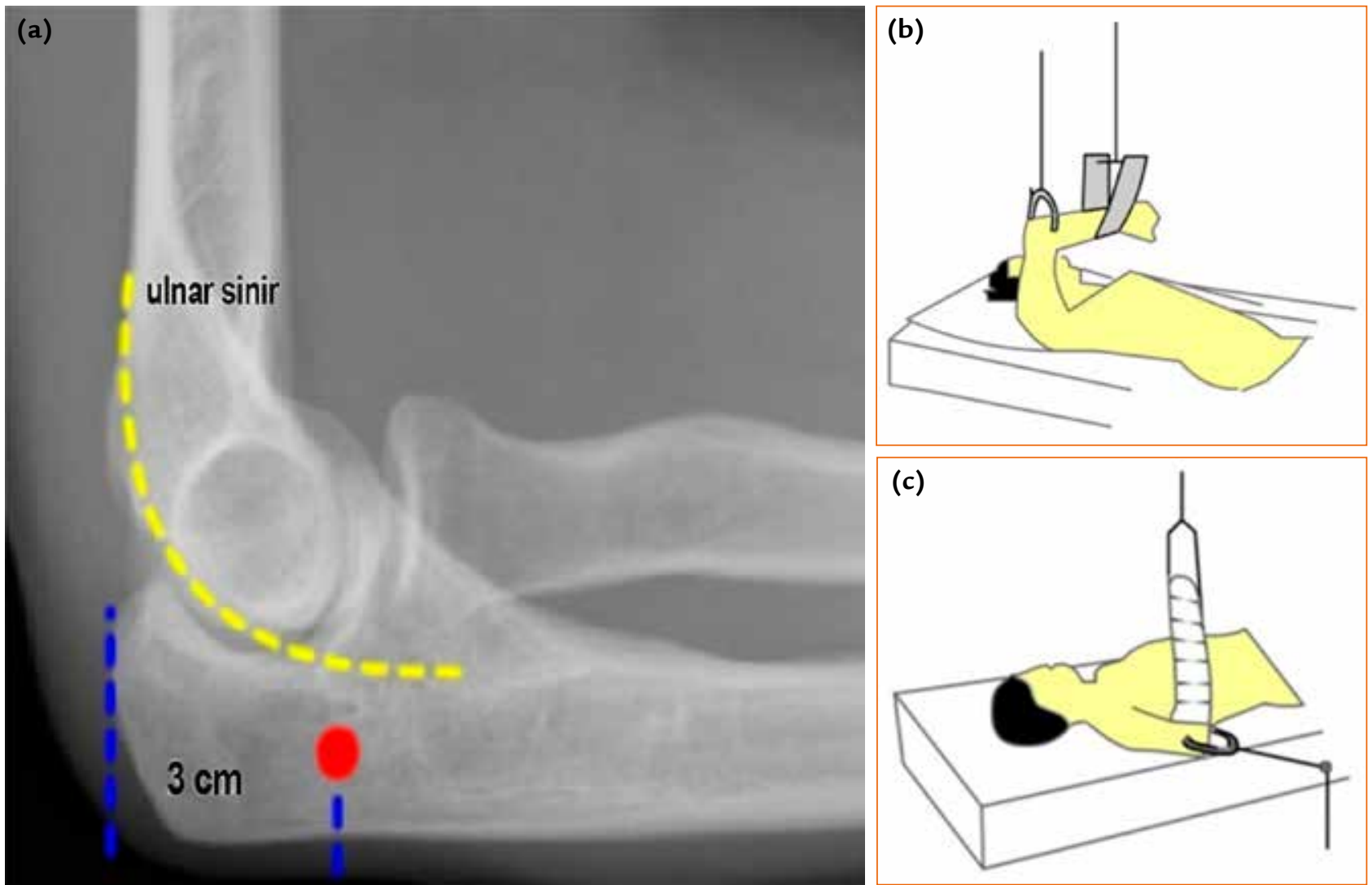

Şekil 6. a-c. Pin giriş yeri (a). Olekranon pin traksiyonu (b). Lateral olekranon traksiyonu (c).

\section{Proksimal Femur}

- Merkeze olan kalça çıkıklarında tercih edilir.

- Traksiyonla birlikte gerilen ligamentum teres ve kapsülün asetabular parçalarını bir miktar redükte ettiği düşünülmektedir.

- Ucu yivli kansellöz pinler kullanılmalıdır.

- Trokanter majorun elle palpe edilebilen çıkıntısının $2,5 \mathrm{~cm}$ aşağısına, femurun ön ve arka planda tam ortasına yerleştirilir. Pinin femur boyun ve başını ortalayacak açıda gönderilmesi önerilir (yaklaşık $15^{\circ}$ anteversiyonda).
- Femurun anterior ve posteriorundaki nörovasküler yapılara dikkat edilmelidir. Femur boynuna, başına ve ekleme pinin zarar vermemesi için azami dikkat gösterilmeli ve işlem floroskopi eşliğinde planlanmalıdır (Şekil 7).

\section{Distal Femur}

- Asetabulum kırıklarında, subtrokanterik kırıklarda (90'a 90 traksiyon) ve proksimal 1/3 femur cisim kırıklarında kullanılır.

- Diğer pin yerleştirilen bölgelere göre nispeten daha güçlü bir traksiyon yapılabilir. 

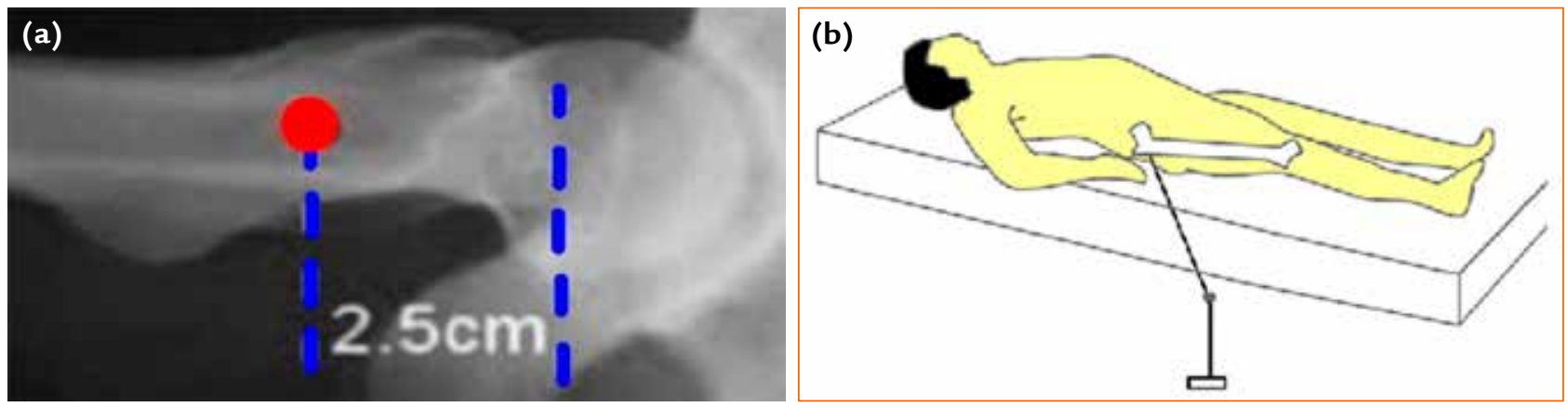

Şekil 7. a, b. Proksimal femur pin giriş yeri (lateral planda) (a). Proksimal femur lateral traksiyonu (b).
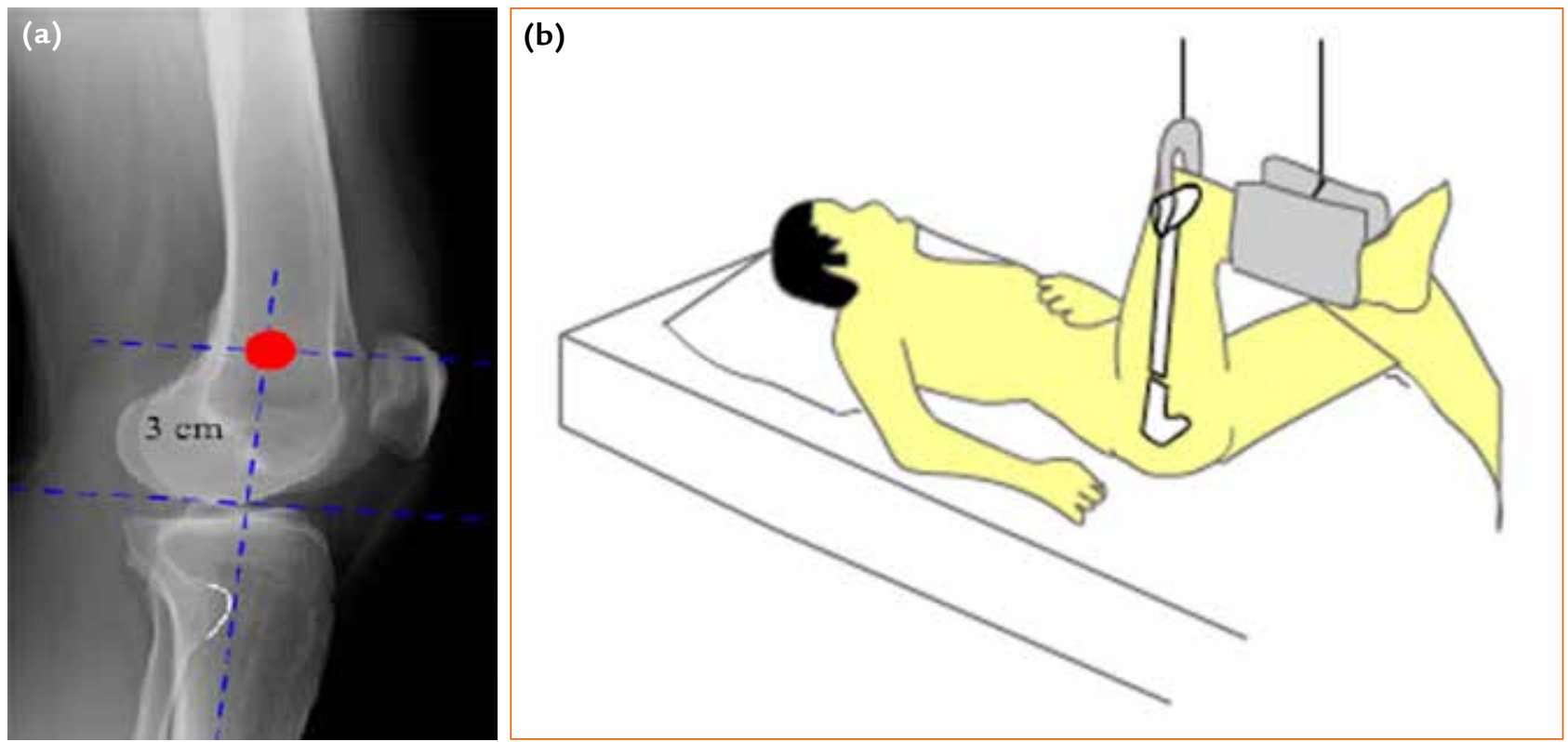

Şekil 8. a, b. Pin giriş yeri (a). Subtrokanterik kırıkta 90’a 90 traksiyon uygulaması (b).

- Diz fleksiyona alınmalı, girişim mediyalden laterale doğru ve mümkünse floroskopi eşliğinde yapılmalıdır.

- Giriş yeri, mediyaldeki adduktor tüberkülün hafif proksimalidir. Eklem çizginin $3 \mathrm{~cm}$ üzerinden çizilen dikey bir çizginin fibula başının anteriorundan çizilen yatay çizgi ile kesiştiği yer, giriş noktasıdır.

- Cilt insizyonu sonrası iliotibial bantta da küçük bir kesi yapılmalıdır.

- Giriş yeri daha distalde olursa interkondiler notch'a penetrasyon ihtimali varken, daha proksimalden girilmesi durumunda Hunter kanalındaki femoral arter risk altındadır (Şekil 8). ${ }^{[11,12]}$

\section{Proksimal Tibia}

- Sıklıkla distal femur $2 / 3$ cisim kırıklarında uygulanmaktadır.

- Epifizi kapanmamış hastalarda yapılmamalıdır (yapilıp zarar verilmesi durumunda rekurvatum deformitesine neden olabilmektedir). ${ }^{[13]}$

- Diz fleksiyona alınarak, işlem lateralden mediyale doğru yapılmaktadır.

- Giriş yeri tuberositas tibia'nın $2,5 \mathrm{~cm}$ distali ve $2,5 \mathrm{~cm}$ posteriorudur. Daha basitçe, tuberositas tibia'nın 2 parmak altı 2 parmak arkası olarak kolaylıkla belirlenebilir (en sık yapılan hata, insizyonun anteriorda kalmasından dolayı, pin yerleşimi sonrası cildin posteriorda gerilmesidir.

- Peroneal sinire dikkat edilmelidir (Şekil 9). ${ }^{[12]}$ 

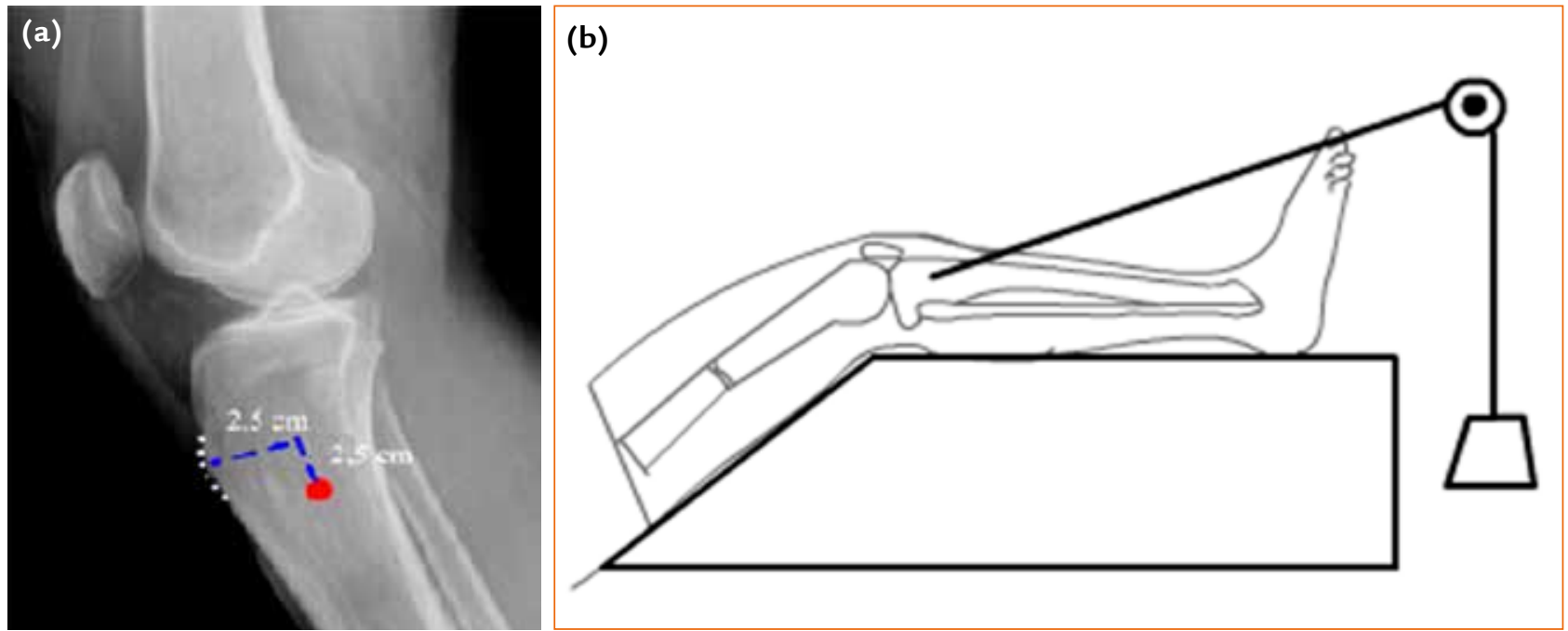

Şekil 9. a, b. Pin giriş yeri (a). Traksiyon sonrası sık uygulanan alt ekstremite pozisyonu (b).
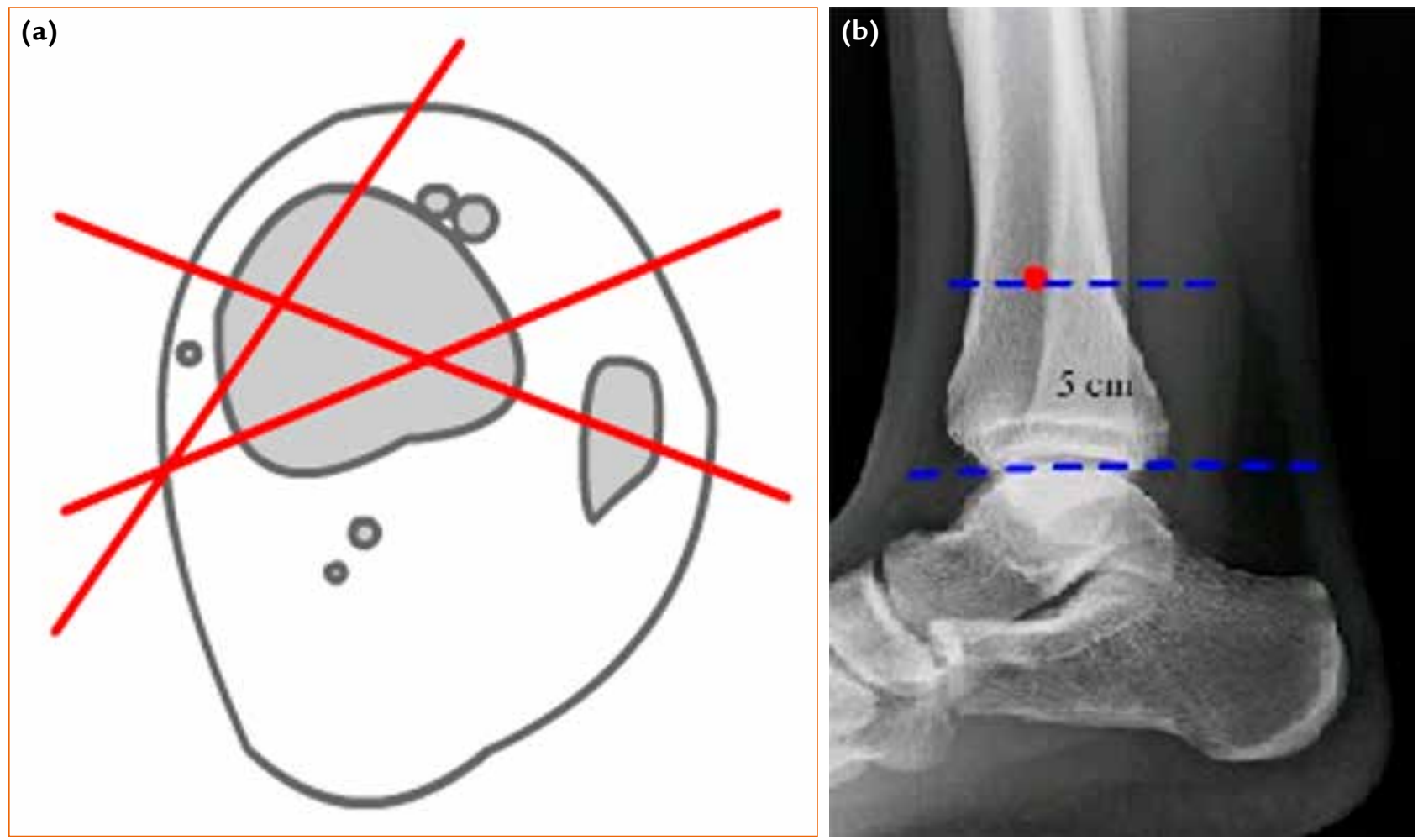

Şekil 10. a, b. Distal tibiada pin yerleşim düzlemleri (a). Pin giriş yeri (b).

\section{Distal Tibia}

Çok sık kullanılmamakla birlikte, tibia plato kırıklarında tercih edilebilir.

Eklem seviyesinin $5 \mathrm{~cm}$ proksimalinde ön arka planda tibiayı ortalayarak, lateralden mediyale doğru pin yerleştirilir.
İki transfiksasyon yöntemi vardır:

1- Transfibular fiksasyon: fibuladan da geçecek şekilde yapılır (peroneal damarlara dikkat edilmelidir.

2- Transvers fiksasyon: sadece tibiaya pin yerleştirilir (safen sinir ve vene dikkat edilmelidir) (Şekil 10). 

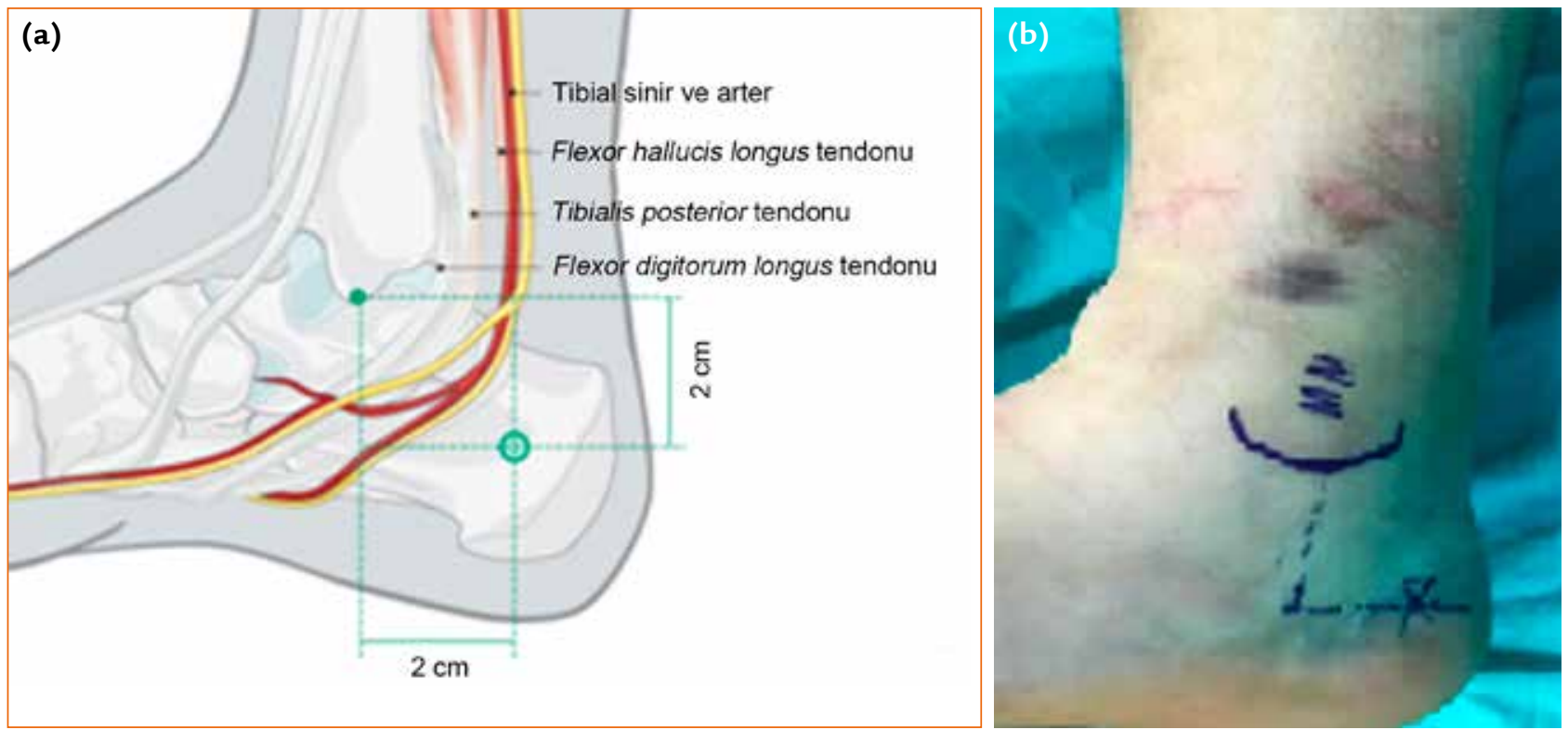

Şekil 11. a, b. Kalkaneus pin giriş yeri ve nörovasküler komşuluklar. (AO Derneği’nin arşivinden)

\section{Kalkaneus}

- Sık kullanılmaktadır.

- Mediyal malleolün $2 \mathrm{~cm}$ posterioru ve $2 \mathrm{~cm}$ inferioru giriş noktasıdır. Daha pratik olarak, mediyal malleolün 2 parmak altı ve 2 parmak arkası pin giriş yeri olarak belirlenebilir.

- Ortası yivli pinler (Denham) tercih edilmelidir.

- Mediyalden laterale doğru pin yerleştirilmelidir.

- Mediyaldeki nörovasküler yapılara ve subtalar ekleme pin yerleştirmemeye dikkat edilmelidir (Şekil 11). ${ }^{[14,15]}$

\section{ISKELET TRAKSIYONU UYGULANMASI SONRASI BAKIM}

İskelet traksiyonu ve traksiyon mekanizmalarının kurulumu sonrası uygun bakım önemlidir. Uzamış hareketsizlik, yatak yaralarına ve olası solunum, idrar veya dolaşım sorunlarına neden olabilir. Günlük yaptırılan egzersiz programı, hastanın kas kuvvetini ve eklem hareketlerini koruyacaktır. Düzenek ve hasta pozisyonu, traksiyon mekanizmasının doğru çalıştığından emin olmak için düzenli olarak kontrol edilmelidir. Osteomiyelit riskinden dolayı, günlük pin dibi pansumanı yapılmalı, pin yerleri takip edilmeli ve profilaktik antibiyotik verilmelidir.

\section{KAYNAKLAR}

1. Khan MJ, Srinivasan VM, Jea AH. The History of Bracing for Scoliosis. Clin Pediatr 2016;55(4):320-5. Crossref

2. Griffiths DL, Brockbank W. Orthopaedic Surgery in the Sixteenth and Seventeenth Centuries Traction Apparatus the Vidian Pictures. J Bone Joint Surg B 1949;31-B(2):313-7. Crossref

3. Vidius V. Chirurgia. 1544.

4. Koval KJ, Zuckerman JD. Handbook of Fractures, 3rd ed. Philadelphia: Lipincott Williams \& Wilkins; 2006.

5. Thakur AJ. Elements of Fracture Fixation-E-book. India: Elsevier Health Sciences; 2015.

6. Pavic R. Prof. Vatroslav Florschütz and the Balkan beam frame. Injury 2011;42(2):225-6. Crossref

7. Salvi AE, Dakovic I, Hacking SA. The invention of the Balkan beam frame. Injury 2009;40(11):1237-8. Crossref

8. Berghausen T, Leslie BM, Ruby LK, Zimbler S. The severely displaced pediatric supracondylar fracture of humerus treated by skeletal traction with olecranon pin. Orthop Rev 1986;15(8):510-5.

9. Millis MB, Singer IJ, Hall JE. Supracondylar fracture of the humerus in children. Further experience with a study in orthopaedic decision-making. Clin Orthop Relat Res 1984;(188):90-7. Crossref

10. Sutton WR, Greene WB, Georgopoulos G, Dameron TB Jr. Displaced supracondylar humeral fractures in children. A comparison of results and costs in patients treated by skeletal traction versus percutaneous pinning. Clin Orthop Relat Res 1992;(278):81-7.

11. Kwon JY, Johnson CE, Appleton P, Rodriguez EK. Lateral femoral traction pin entry: risk to the femoral artery and other medial neurovascular structures. J Orthop Surg Res 2010;5(1):4. Crossref 
12. Wheeless CR 3rd. Wheeless' textbook of orthopaedics. http:// www.wheelessonline.com/ [Date of last update: March 4, 2018]

13. Pappas AM, Anas P, Toczylowski JH. Asymmetrical arrest of the proximal tibial physis and genu recurvatum deformity. J Bone Joint Surg Am 1984;66(4):575-81. Crossref

14. Casey D, McConnell T, Parekh S, Tornetta P. Percutaneous pin placement in the medial calcaneus: is anywhere safe? J Orthop Trauma 2002;16(1):26-9. Crossref
15. Hessmann $M$, Nork $\mathrm{S}$, Sommer $\mathrm{C}$, Twaddle B. AO surgery reference: traction (initial provisional stabilization). https:// www2.aofoundation.org/wps/portal/surgery?showPage $=$ redfix\&bone=Tibia\&segment $=$ Distal\&classification $=43$ A3\&treatment=\&method=Traction\%20-\%20 (initial\%20 provisional\%20stabilization $) \& i m p l a n t s t y p e=\& a p p r o a c h=\&$ redfix url=1285238986320\&Language $=$ en [Accessed: 3 Dec, 2008]. 